Research Paper

\title{
Bionanocomposites produced from cassava starch and oil palm mesocarp cellulose nanowhiskers
}

\author{
Adriana de Campos ${ }^{\mathrm{a}, *}$, Alfredo R. de Sena Neto ${ }^{\mathrm{a}}$, Vanessa B. Rodrigues ${ }^{\mathrm{a}, \mathrm{b}}$, \\ Bruno R. Luchesi ${ }^{a, c}$, Francys K.V. Moreira ${ }^{a, c}$, Ana Carolina Correa ${ }^{a}$, Luiz H.C. Mattoso ${ }^{a}$, \\ José M. Marconcini ${ }^{\text {a }}$ \\ a Nanotechnology National Laboratory for Agriculture (LNNA), Embrapa Instrumentation, São Carlos, SP, Brazil \\ ${ }^{\mathrm{b}}$ Federal University of São Carlos, Department of Chemistry, São Carlos, SP, 13565-905, Brazil \\ ${ }^{c}$ Federal University of São Carlos, Department of Materials Engineering, São Carlos, SP, 13565-905, Brazil
}

\section{A R T I C L E I N F O}

\section{Article history:}

Received 22 March 2017

Received in revised form 27 July 2017

Accepted 27 July 2017

Available online 3 August 2017

\section{Keywords:}

Cassava starch

Oil palm mesocarp fibers

Nanowhiskers

Cellulose

Nanocomposites

\begin{abstract}
A B S T R A C T
Cassava starch films reinforced with cellulose nanowhiskers from oil palm mesocarp fibers were produced by casting. Nanowhiskers were obtained by sulphuric acid hydrolysis followed by microfluidization and incorporated in starch films at various loadings (1-10 wt\%). Morphological and mechanical characterizations showed that the reinforcing effect of oil palm cellulose nanowhiskers was significant at loadings of up to $6 \mathrm{wt} \%$, which was determined to be the nanowhiskers percolation threshold. Above this content, formation of agglomerates became more significant, causing a decrease in mechanical properties of starch bionanocomposites. Below percolation threshold, such as $2 \mathrm{wt} \%$, elongation at break increased by $70 \%$, showing an effective reinforcing effect. Dynamic mechanical analyses revealed filler/matrix interactions through hydrogen bonding in bionanocomposites.
\end{abstract}

(c) 2017 Elsevier Ltd. All rights reserved.

\section{Introduction}

The development of sustainable and biodegradable materials using natural and renewable resources with the aim to produce eco-friendly packaging is one of the biggest challenges of modern industries (Benhamou, Dufresne, Magnin, Mortha, \& Kaddami, 2014). Among the many known biodegradable materials, starch is one of the most promising for biodegradable plastics applications because of its abundant supply and low cost, in addition to the possibility of being processed at large scale in conventional polymer processing equipments (Cao, Chang, \& Huneault, 2008; Dufresne \& Castao, 2017). However, starch plastics possess some disadvantages such as low resistance at high temperatures, humidity and low flexibility (Kaisangsri, Kerdchoechuen, \& Laohakunjit, 2014). In this way, the incorporation of cellulose nanowhiskers (CNWs) can increase mechanical and water barrier properties of starch plastics. CNWs are interesting fillers for starch matrices due to their similar chemical structures, which tends to enhance filler/matrix interfacial compatibility through hydrogen bonding (Liu, Dong, Bhattacharyya, \& Sui, 2017).

\footnotetext{
* Corresponding author.

E-mail address: dridecampos@yahoo.com.br (A.d. Campos).
}

The use of agro-residues as raw materials for CNW production can add value to biodegradable processed materials, when utilized as a reinforcing filler in polymer composites (Arrieta, Fortunati, Dominici, López, \& Kenny, 2015; Li et al., 2015; Pasquini, Teixeira, Curvelo, Belgacem, \& Dufresne, 2010). Cellulose generated from palm oil production could be used as a reinforcing filler for starch. Palm oil industry generates a large amount of cellulose-rich residues that have been associated with environmental problems due to their improper disposal (Sreekala, Kumaran, \& Thomas, 1997). Adding value to this agro-residue may benefit the palm oil production chain, as even its waste could be considered as a source of cellulose and renewable feedstock (Lamaming et al., 2015). Oil palm mesocarp fiber (OPMF), for example, is the fiber obtained after extracting palm oil from fruit mesocarp. OPMF contains, on a dry weight basis, approximately 35\% holocellulose, 44\% lignin, $16 \%$ extractives and 5\% ash (Campos et al., 2017), which represents higher cellulose content in comparison with coir, sugarcane bagasse and kenaf fibers (Lani, Ngadi, Johari, \& Jusoh, 2014).

A significant amount of OPMF can be used as a source of CNWs after chemical and/or physical treatments (Ferrer, Filpponen, Rodríguez, Laine, \& Rojas, 2012). The possible uses of CNWs include the production of biopolymer composites, percolated gels and aerogels (Camargo et al., 2016). Nanocellulose can also be applied as a reinforcing filler in polymers for automotive industry, construc- 
tion, packaging, electronics and aerospace due to the industrial plants that already begun to operate worldwide (Celluforce, 2011), making CNWs usable in commercial high value-added products applications.

CNWs are usually isolated by acid hydrolysis, which removes acid soluble amorphous regions of lignocellulosic fibers, leading to an increase in crystallinity. Commonly used acids are hydrochloric and sulfuric acid. Prior to acid hydrolysis, a common pretreatment named bleaching is performed, which removes chromophoric substances and residual lignin (Souza et al., 2015). Fahma, Takemura, and Saito (2014) studied cellulose nanofibers (CNF) extraction from oil palm empty-fruit fibers using sulfuric acid solution at $45^{\circ} \mathrm{C}$ for 60 min. The authors obtained entangled CNF with 1-2 $\mu \mathrm{m}$ length and crystallinity around 50\%. Souza et al. (2015) studied the extraction of CNF from OPMF using a hydrolysis time of $150 \mathrm{~min}$. The authors obtained CNF with a length of about $171 \mathrm{~nm}$ and crystallinity of 70\%. Miao et al. (2016) investigated the properties of CNF extracted from cotton using alkali treatment followed by Tempooxidized. They obtained nanofibers with several micrometers long and $5-10 \mathrm{~nm}$ of diameter and crystallinity of $72 \%$. Santana et al. (2017) studied nanofibers from sisal that were obtained by chemical treatment, resulting in nanofibers with length of $302 \mathrm{~nm}$ and diameter of $12.7 \mathrm{~nm}$.

The present study describes the incorporation of CNWs, obtained from oil palm mesocarp fiber via sulfuric acid hydrolysis and microfluidization, in cassava starch films produced by casting. Campos et al. (2017) showed that mechanical shearing treatment (microfluidizer) did not decrease the length and diameter of CNWs, but maintained similar average dimensions obtained after 105 min of acid hydrolysis. Differently of ultrasonic treatment that reduced the diameter of CNWs, microfluidization improved the homogeneity of nanocellulose morphology in suspension and reduced agglomerates, thereby reducing the chemical reaction time necessary to obtain stable nanostructures in suspension.

Solikhin, Hadi, Massijaya, and Nikmatin (2016) examined the isolation of nanofibers from oil palm empty fruit bunch (OPEFB) by mechanical processes, and obtained nanofibers with diameter above $100 \mathrm{~nm}$ using 7 milling times. Nikmatin, Syafiuddin, and Irwanto (2017) studied the effect of nano powder and long OPEFB fibers obtained by milling process in synthetic polymer matrix. They observed that composites with nano fillers presented higher elastic modulus with the increase of filler loading, while mechanical properties of composites with long fibrous fillers reduced with the increase of filler loading.

It is recognized that the strong interfacial interaction between CNWs and polymer matrices is attributed to well-dispersed nanofibers (Liu et al., 2017). Starch-based nanocomposites were investigated by Liu et al. (2017) using starch sandwiches prepared by casting with CNWs from flax yarns. They demonstrated that both filler/matrix interaction and solvent evaporation rate play a role on the dispersion of CNWs within starch matrix. Balakrishnan, Sreekala, Kunaver, Huskić, and Thomas (2017) investigated the viscoelastic properties of $\mathrm{CNW} /$ starch nanocomposites and observed that starch macromolecular chains are confined on the CNW surface and that effective reinforcing effect occurs for CNW loadings of up to $3 \%$.

However, there is a lack of information about the role played by CNWs extracted from OPMF on the properties of starch nanocomposites. To the best of our knowledge, this study is the first to consider the use of CNWs from oil palm cellulosic residue as a reinforcing filler for starch. OPMF is advantageous over other nanowhiskers sources because it is a residue typically associated with environmental problems, thus its reuse as a raw material for cellulose nanostructures production could positively add value to the entire oil palm industry. Herein, CNWs extracted from OPMF were first characterized with respect to their morphology by scanning transmission electron microscopy (STEM), and crystallinity by X-ray diffraction (XRD). The influence of OPMF-CNWs on the morphology, crystallinity, structural (FTIR), mechanical and thermo-mechanical properties of starch nanocomposites were investigated.

\section{Materials and methods}

\subsection{Materials}

Unpurified oil palm mesocarp fibers (OPMF) were kindly supplied by Embrapa Amazonia Oriental (Belém, Pará, Brazil). Hydrogen peroxide (Synth) and $\mathrm{NaOH}$ (Qhemis) were used for delignifying and bleaching OPMF. Bleached OPMF were hydrolyzed with sulfuric acid (Synth) and cellulose membrane (Sigma-Aldrich: D9402) was used to dialyze the nanowhiskers in acid suspension. Cassava starch (18 wt\% amylose and $82 \mathrm{wt} \%$ amylopectin) was supplied by Amazon Amidos (Pará, Brazil).

\subsection{Preparation of nanowhiskers from $O P M F$}

Oil palm mesocarp fibers (OPMF) were ground in a Wiley mill through a 7 mesh sieve and dried at $50^{\circ} \mathrm{C}$ in an air circulating oven for $24 \mathrm{~h}$. The delignifying treatment of OPMF was carried out with a $2 \%(\mathrm{~m} / \mathrm{v}) \mathrm{NaOH}$ solution at $70^{\circ} \mathrm{C}$ for $60 \mathrm{~min}$ under constant stirring. The mixture was brought to room temperature $\left(25^{\circ} \mathrm{C}\right)$, filtered and neutralized with distilled water. The delignified OPMF were dried at $50^{\circ} \mathrm{C}$ and further bleached with a mixture of $\mathrm{NaOH}(5 \%$, $\mathrm{m} / \mathrm{v})$ and $\mathrm{H}_{2} \mathrm{O}_{2}(10 \%, \mathrm{v} / \mathrm{v})$ solution at $55^{\circ} \mathrm{C}$ under mechanical stirring for $90 \mathrm{~min}$. The bleaching process was done twice in order to remove attain a high cellulose purification extent. Bleached OPMF were cooled to room temperature, washed with distilled water until neutrality, and finally dried in an air circulation oven at $50^{\circ} \mathrm{C}$.

CNW from OPMF were obtained by adding $5 \mathrm{~g}$ of bleached OPMF to $100 \mathrm{~mL}$ of $6 \mathrm{~mol} \mathrm{~L}^{-1}$ sulfuric acid solution under mechanical stirring. Acid hydrolysis was carried out at $45^{\circ} \mathrm{C}$ for $105 \mathrm{~min}$. The resulted suspension was diluted to $500 \mathrm{~mL}$ of cold deionized water to quench the reaction, washed by successive centrifugation cycles of $10,000 \mathrm{rpm}$ for $10 \mathrm{~min}$, and then dialyzed incellulose membranes against deionized water until suspension reached $\mathrm{pH}$ 6-7. Finally, the suspension was microfluidizated through 16 passes at 30,000 psi. Ice bath was used to avoid excessive heating.

\subsection{Preparation of starch/OPMF nanowhisker bionanocomposites}

Neat starch film was obtained by solvent-cast of aqueous mixtures comprising $75 \mathrm{wt} \%$ cassava starch, $23 \mathrm{wt} \%$ glycerol and $35 \mathrm{wt} \%$ of deionized water. Each mixture was solubilized at $90^{\circ} \mathrm{C}$ for $1 \mathrm{~h}$ in a water batch. Afterwards, the mixture was spreadon aflat and uniform plate. The film-forming process was conducted in an air circulating oven at $50^{\circ} \mathrm{C}$ for $17 \mathrm{~h}$. Starch/OPMF nanowhisker bionanocomposites were formed by adding OPMF nanowhiskers at contents of 1, 2, 3, 6 and $10 \mathrm{wt} \%$ based on the cassava starch mass. All films were previously conditioned at $50 \% \mathrm{RH}$ for at least $48 \mathrm{~h}$ prior to characterizations.

\subsection{Characterizations}

\subsubsection{Scanning transmission electron microscopy (STEM)}

A drop of diluted nanowhiskers suspension (OPMF-CNW obtained by acid hydrolysis for 105 min followed by mechanical shearing (microfluidizer), $\mathrm{CNW}_{105+\mathrm{MF}}$ ) was deposited on a 400-mesh formvar-carbon $\mathrm{Cu}$ grid, which was stained with $1.5 \%$ aqueous uranyl acetatesolution and allowed to dry at room temperature. TEM analysis of $\mathrm{CNW}_{105+\mathrm{MF}}$ was performed on a Tecnai ${ }^{\mathrm{TM}} \mathrm{G} 2$ F20 electron microscope (FEI Company, Hillsboro, Or). The images 

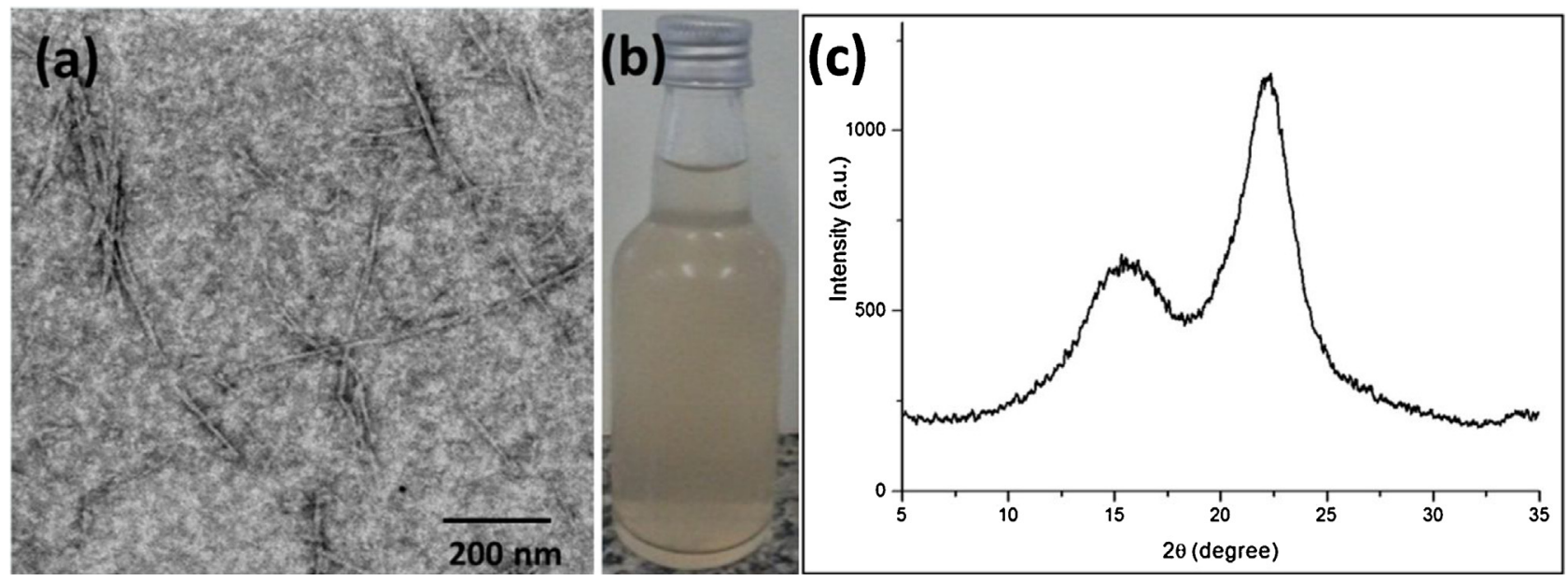

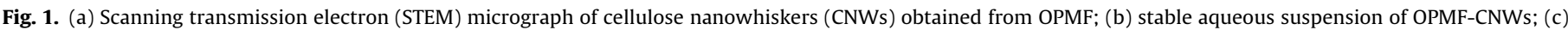
XRD pattern of OPMF-CNWs.

were acquired in the scanning transmission electron microscopy (STEM) in bright-field (BF) mode.

\subsubsection{X-ray diffraction (XRD)}

XRD patterns were measured in a Lab X-XRD 6000 diffractometer (Shimadzu) employing CuK $\alpha$ radiation $(\lambda=1.5406 \AA$ ) at $30 \mathrm{kV}$ and $30 \mathrm{~mA}$. The crystallinity index $\left(C_{I}\right)$ of OPMF-CNW and film samples were determined by the Lorentzian deconvolution method using the software Magic Plot Student 2.5.1.

\subsubsection{Field emission gun scanning electron microscopy (FEG-SEM)}

A Philips XL30 microscope was used to perform FEG-SEM on OPMF-CNW and bionanocomposites at accelerating voltage of $5 \mathrm{kV}$. Samples were mounted onto aluminum specimen stubs using double-sided adhesive carbon tapes and further coated with a thin carbon layer. Micrographs were recorded using the secondary electron (SE) mode.

\subsubsection{Dynamic mechanical thermal analysis (DMTA)}

Dynamic mechanical thermal analyses were performed on strip specimens previously conditioned at 50\% RH. A Q600 dynamic analyzer (TA Instruments) was used in the tension film clamp mode, with a standard heating rate of $2^{\circ} \mathrm{min}^{-1}$, amplitude of $10 \mu \mathrm{m}$ and frequency of $1 \mathrm{~Hz}$. Film samples were scanned from -100 to $50^{\circ} \mathrm{C}$ to record their storage modulus $\left(E^{\prime}\right)$ and damping factor $(\tan \delta)$ as a function of temperature.

\subsubsection{Mechanical tests}

Mechanical tests were performed on an EMIC DL3000 universal testing machine (EMIC, Paraná, Brazil) operating with cross-head speed of $5 \mathrm{~mm} \mathrm{~min}^{-1}$ and $50 \mathrm{Kgf}$ load cell. Tests were carried out as per ASTM D882 protocol (2013). Significant differences among tensile strength, elongation at break and elastic modulus values were determined at $5 \%$ significance level by analysis of Variance (ANOVA) and Games-Howell comparative analyses to indicate cases with heterogeneity of variance between treatments. Statistical analyses were performed with R software, version 3.3.3.

\section{Results and discussion}

Fig. 1(a) shows STEM micrograph of OPMF cellulose nanowhiskers. The average length (L) and diameter (D) were $104 \pm 52 \mathrm{~nm}$ and $9 \pm 4 \mathrm{~nm}$, respectively, leading to an aspect ratio (L/D) of 12 . This small aspect ratio compared with other CNWs obtained by acid hydrolysis, for example $258-269 \mathrm{~nm}$ of length and 2.3-3.2 nm of diameter for sisal CNWs (Santana et al., 2017), $302 \mathrm{~nm}$ of length and $12.7 \mathrm{~nm}$ of diameter for cassava root bagasse CNWs (Leite, Zanon, \& Menegalli, 2017), is due to mechanical shearing (microfluidization) imposed on OPMF-CNW. Microfluidization probably broke down both amorphous and crystalline portions of OPMF-CNWs, however, it improved the stability of the CNW suspension, which did not form precipitates over long times, as shown in Fig. 1(b). The XRD pattern of the OPMF-CNWs (Fig. 1(c)) is characteristic of cellulose I and their crystallinity index $\left(C_{I}\right)$ was $70 \%$.

The aspect ratio of OPMF-CNWs was used to calculate the percolation threshold $\left(v_{R C}\right)$ as 5.8 in vol\% or 8.1 in wt\% using Eq. (1) (Garcia de Rodriguez, Thielemans, \& Dufresne, 2006). The volume to mass conversion was calculated using the density of starch $\left(1.4 \mathrm{~g} \mathrm{~cm}^{-3}\right)$. The OPMF-CNW contents investigated in this study (1-10 wt\%) were above and below the percolation threshold.

$v_{R C}=\frac{0.7}{L / D}$

SEM-FEG micrographs of starch bionanocomposites containing $(1-10 \mathrm{wt} \%)$ of OPMF-CNWs are presented in Fig. 2. The nanowhiskers appear as shiny dots in all bionanocomposites samples, as indicated by arrows. Some agglomerates are evident (Fig. 2c-f), indicating an incomplete dispersion of OPMF-CNWs within the starch matrix. This result is expected because the concentration of $10 \mathrm{wt} \%$ is above the OPMF-CNW percolation threshold $v_{R C}$.

XRD patterns of starch bionanocomposites with OPMF-CNW are shown in Fig. 3. Adding OPMF-CNWs to starch resulted in new peaks at $16.9^{\circ}, 19.8^{\circ}$ and $22.2^{\circ}$ of $2 \theta$ in the XRD pattern of bionanocomposites (Fig. 3e). Generally, starch form V-type crystals due to complexation between amylose and glycerol (Campos, Teodoro et al., 2013; Campos, Tonoli et al., 2013; Magalh\&es \& Andrade, 2009). Such crystallization depends on the hydration degree and can be classified as $\mathrm{V}_{\mathrm{A}}$-type unit cell, which is less hydrated than the $V_{H^{-}}$type unit cell. In Fig. 3 , the peak at $2 \theta=16.6^{\circ}$ increased in intensity with increasing OPMF-CNW loading. This may be related to recrystallization of amylopectin induced by OPMF-CNW (Campos, Teodoro et al., 2013; Campos, Tonoli et al., 2013; van Soest, Hulleman, de Wit, \& Vliegenthart, 1996), because amylopectin chains tend to crystallize on the CNW surface (Santana et al., 2017). The peak at $2 \theta=19^{\circ}$ may correspond to $\mathrm{V}_{\mathrm{H}^{-}}$-type of starch crystal, which also tends to increase in intensity with increasing OPMF-CNW loading. The peak at $2 \theta=20.5^{\circ}$ is observed in 

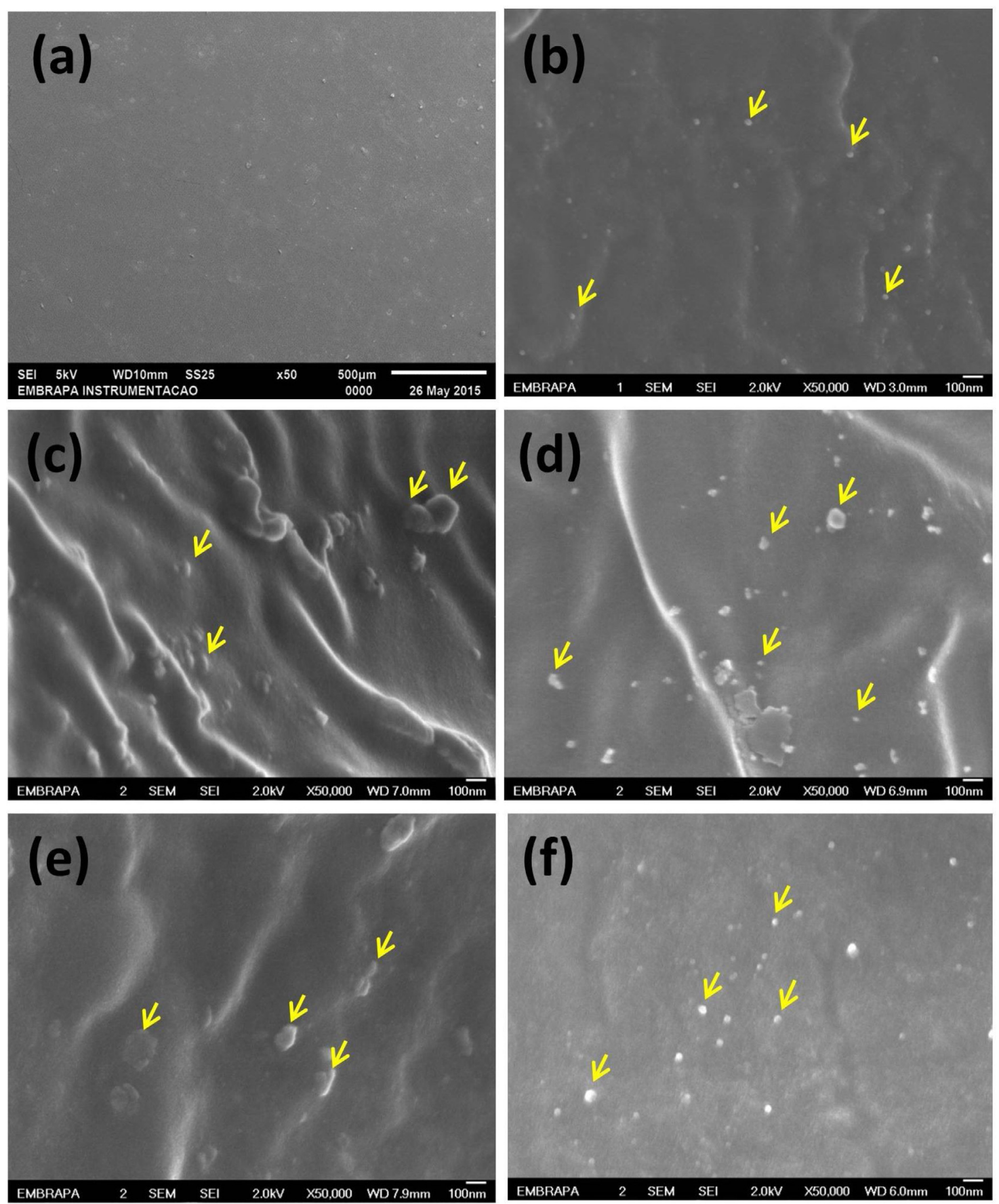

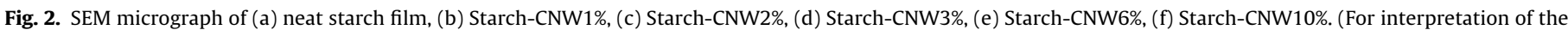
references to colour in the text, the reader is referred to the web version of this article.)

the bionanocomposite loaded with $6 \mathrm{wt} \%$ and $10 \mathrm{wt} \%$ OPMF-CNW (Fig. 3e and f, respectively) corresponding most likely to the 002 lattice plane of OPMF-CNW (Fig. 3g). But it may also be related to the $\mathrm{V}_{\mathrm{H}}$-type crystalline structure of starch (van Soest et al., 1996).

It is clear from Fig. 3 that inclusion of OPMF-CNW induced retrogradation of cassava starch films through a nucleating effect, as expected. This was particularly supported by the increased $C_{I}$ of bionanocomposite films compared to that of neat cassava starch film, which presented a no significant residual A-type crystallinity (Table 1). Fig. 3(B) shows representative deconvoluted peaks used to estimate the $C_{I}$ of cassava starch film samples.

Nanowhiskers agglomeration is also expected to occur when the $\mathrm{CNW}$ loading is above $v_{R C}$ (starch bionanocomposite filled
Table 1

Crystallinity index $\left(C_{I}\right)$ of neat cassava starch films, neat OPMF-CNW and their resulting bionanocomposite films comprising up to $10 \mathrm{wt} \%$ OPMF-CNW.

\begin{tabular}{ll}
\hline Sample & $C_{I}(\%)$ \\
\hline Neat starch film & - \\
Starch film -1 wt\% CNW & 7 \\
Starch film -2 wt\% CNW & 8 \\
Starch film -3wt\% CNW & 8.5 \\
Starch film -6wt\% CNW & 11 \\
Starch film -10 wt\% CNW & 20 \\
OPMF-CNW & 70
\end{tabular}



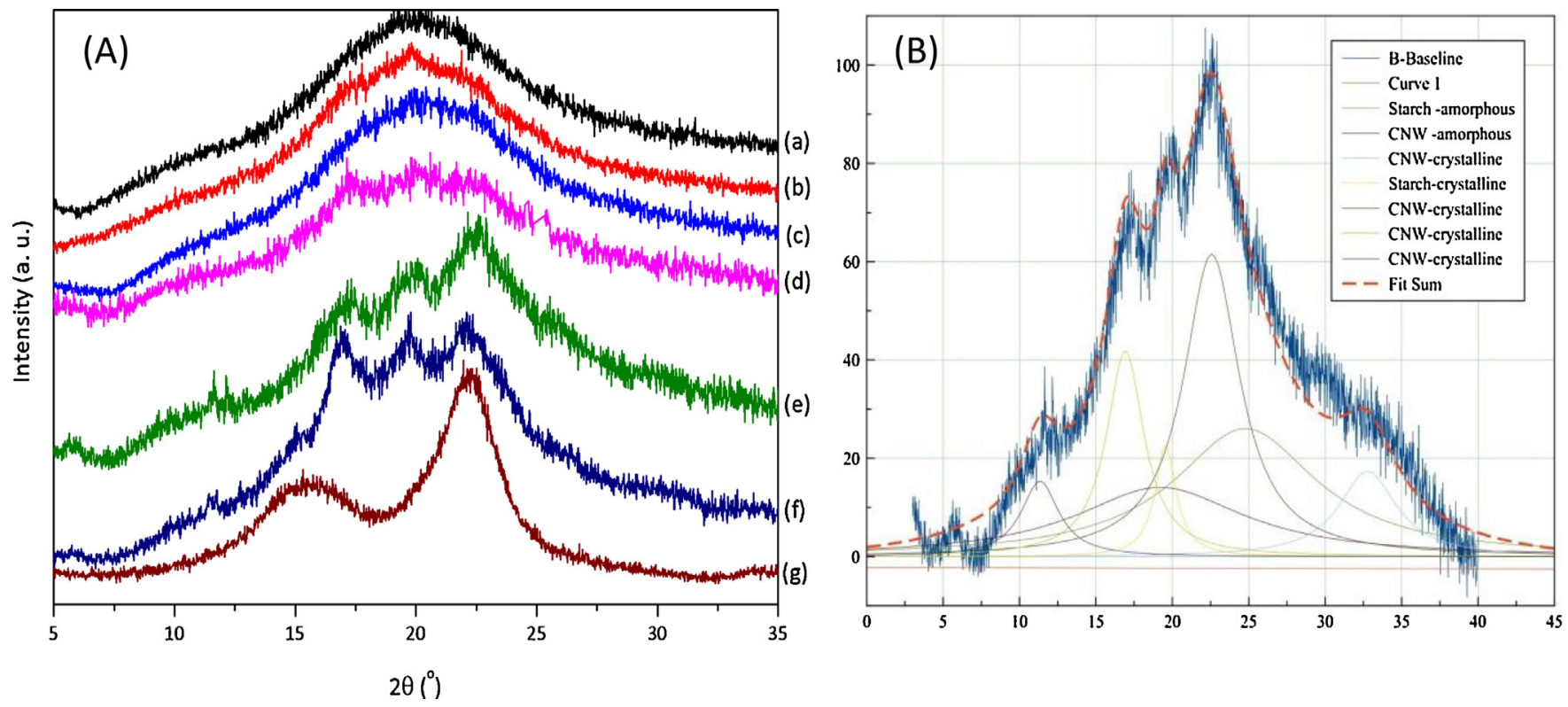

Fig. 3. XRD patterns of neat starch film (a) and its respective bionanocomposites loaded with $1 \%$ (b) $2 \%$ (c) $3 \%$ (d) $6 \%$ (e) $10 \%$ (f) OPMF-CNWs (in wt\%).

with 10 wt\% OPMF-CNW), consequently starch/CNW interactions decrease and the peak at $20.5^{\circ}$ is less pronounced. Inclusion of cellulose nanowhiskers in an starch matrix may also cause typical peaks of starch to shift (Campos, Teodoro et al., 2013; Campos, Tonoli et al., 2013).

The thermomechanical behavior of neat starch films and the bionanocomposites containing 1, 6 and $10 \mathrm{wt} \%$ OPMF-CNWs was examined by DMTA, Fig. 4 . The $20 \mathrm{wt} \%$ glycerol used to plasticize the starch matrix resulted in a biphasic structure due to the partial miscibility between starch and glycerol. This can be seen by the two decays in the temperature-dependent evolution of storage modulus ( $\left.\log \mathrm{E}^{\prime}\right)$, Fig. 4a, and in parallel, two $\tan \delta$ peaks revealed in Fig. 4b. The first transition centered at approximately $-49^{\circ} \mathrm{C}$ can be ascribed to $\alpha$-relaxation of glycerol-rich phase, while the second transition beginning at $0{ }^{\circ} \mathrm{C}$ corresponds to $\alpha$-relaxation of starchrich phase (Curvelo, Carvalho, \& Agnelli, 2001; Mathew \& Dufresne, 2002). Fig. 4a shows that OPMF-CNWs did not reinforce the plasticized starch matrix at the glassy state $\left(\mathrm{T}<0{ }^{\circ} \mathrm{C}\right)$, however their reinforcing effect was noticeable at ambient temperatures (Fig. 4a, insert). This is most likely due to the great ability of OPMF-CNW to restrict motions of the softened starch matrix.

All bionanocomposites presented higher crystallinity than neat starch film and consequently they were more brittle due to the higher stiffness of crystalline domains nucleated by OPMF-CNW. Below glass transition temperature $\left(-80^{\circ} \mathrm{C}\right)$, it was observed the storage modulus decreased with the increase of OPMF-CNW content. This behavior could be explained by the decrease in the amorphous phase chains mobility that was anchored by crystalline domains introduced by the OPMF-CNWs. It was observed that above $23^{\circ} \mathrm{C}$, the mobility of amorphous phase chains increased. Bionanocomposites that have greater crystallinity than neat starch film had higher fraction of crystalline domains anchoring amorphous phase chain, decreasing its mobility, which reflects in the larger storage modulus above the $\alpha$-relaxation transition temperature.

The effect of OPMF-CNWs on the $\tan \delta$ vs. temperature curves is demonstrated in Fig. 4b. The addition of OPMF-CNW shifted the first peak toward higher temperatures, being this displacement evident for loadings as low as $1 \mathrm{wt} \%$. The position of the second peak was found to be independent on the OPMF-CNW loading. These results corroborate with previous studies, where higher affinity of

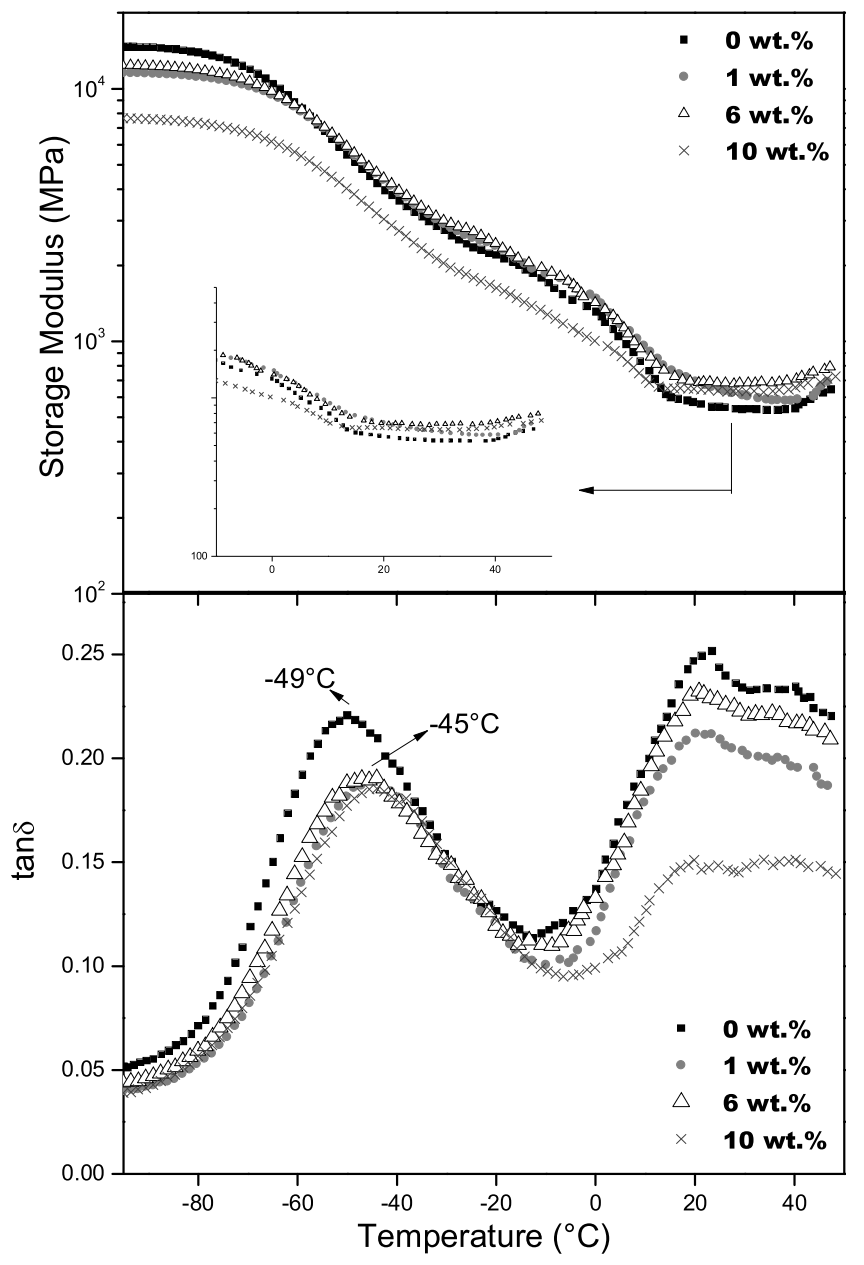

Fig. 4. Evolution of (a) logarithm storage modulus ( $\left.E^{\prime}\right)$ and (b) $\tan \delta$ upon increasing temperature of $20 \mathrm{wt} \%$ glycerol plasticized starch film and its respective bionanocomposites with OPMF-CNWs. 

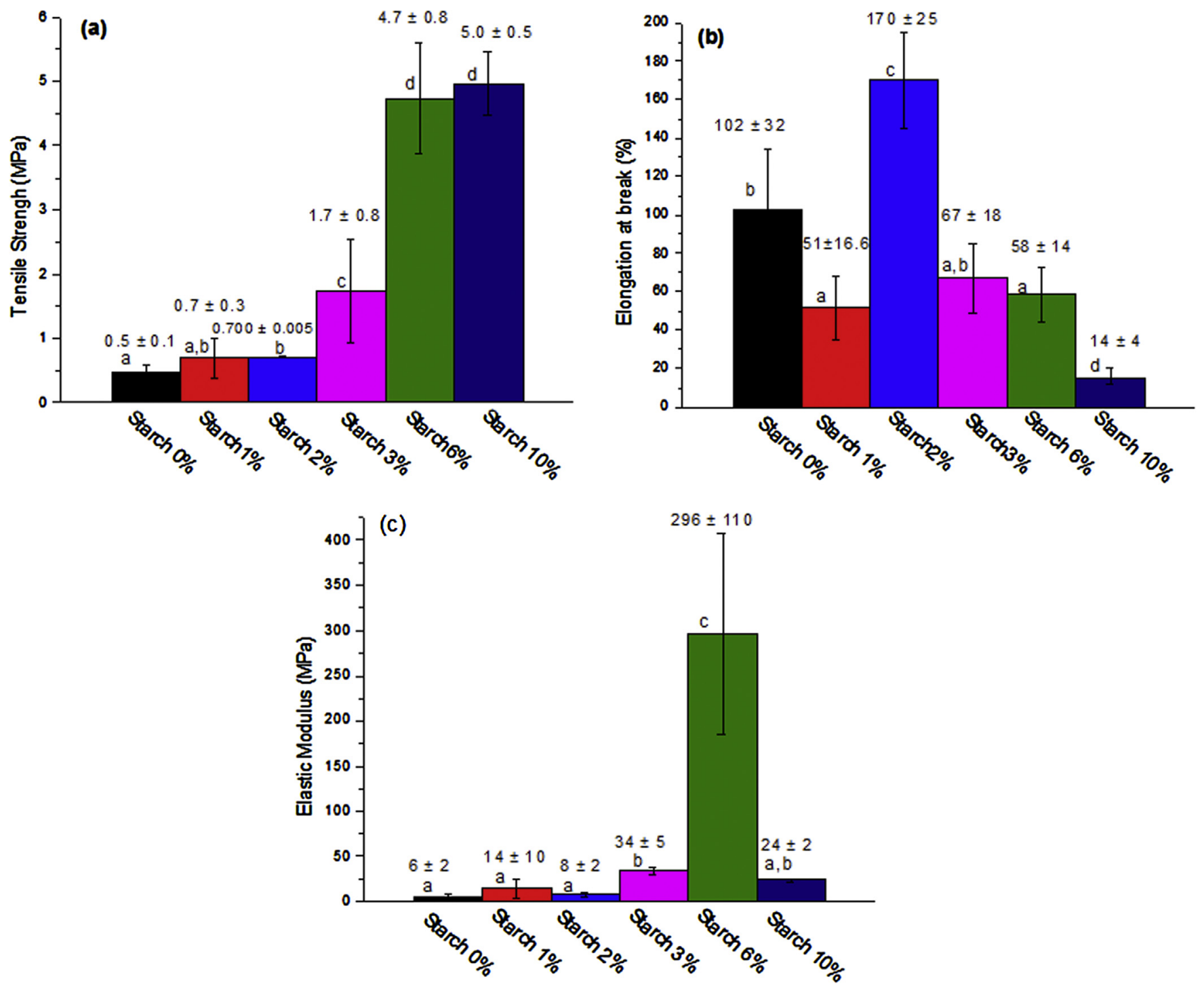

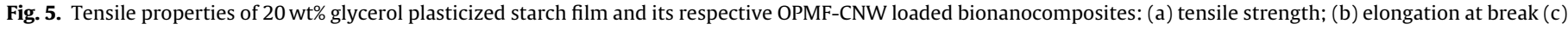
elastic modulus.

glycerol to CNWs rather than starch, and its consequent migration to the $\mathrm{CNW} /$ starch matrix interface were reported (Anglès \& Dufresne, 2001; Balakrishnan et al., 2017; Teixeira et al., 2009). The results presented in Fig. 4 show an overall stiffening of starch due to the presence of OPMF-CNWs, which suggest effective filler/matrix interaction through hydrogen bonding in the bionanocomposites.

Tensile properties of OPMF-CNW/starch bionanocomposites have been listed in Fig. 5. It was verified a gradual increase in tensile strength and reduction in elongation at break with increasing OPMF-CNW loading. The higher tensile strength revealed in the bionanocomposites is due to the increased stiffness of the material imposed by the OPMF-CNWs when they exhibit good adhesion to the starch matrix. There was an increase of elongation at break of $240 \%$ with addition of 3 wt\% OPMF-CNW due to good compatibility and interfacial adhesion, which lead to an effective stress transference from starch matrix to the OPMF-CNWs. At this loading, the OPMF-CNWs were well dispersed throughout the matrix because this amount was below the percolation threshold. Also, there was an abrupt increase in tensile strength and elastic modulus of the nanocomposite with addition of $6 \mathrm{wt} \%$ OPMF-CNW, however, the introduction of $10 \mathrm{wt} \%$ OPMF-CNW caused a decrease in elastic modulus. This could be associated with excessive fiber/fiber contact, resulting in an inefficient stress transfer in the OPMFCNW/starch bionanocomposites. On the other hand, Santana et al. (2017) evaluated the mechanical properties of sisal nanofibers (0-5\%) reinforced cassava starch films, whose elastic modulus was of around $2.2 \mathrm{GPa}$. Statistical analyses revealed significant differences $(p<0.05)$ in tensile strength and elastic modulus when the OPMF-CNW loadings were above $3 \%$. However, above percolation threshold (6\%), there were no significant differences of mechanical performance among the starch/OPMF-CNW bionanocomposites.

The effective wetting and uniform dispersion of CNWs within polymer matrices and a strong nanowhiskers/matrix adhesion are required to obtain CNW-based nanocomposites with improved mechanical performance. The results presented in Fig. 5 proved that CNWs from oil palm are suitable as reinforcing fillers for biodegradable starch plastics.

Salehudin, Salleh, Muhamad, and Mamat (2014) used cellulose from oil palm empty-fruit bunch (OPEFB) to obtain whiskers of about $50-90 \mathrm{~nm}$ diameter to reinforce starch films produced by casting. They observed that mechanical properties were reduced when cellulose nanofiber goes beyond $2 \%$ in mass content. In the present work, it was observed an increase in elastic modulus of starch matrix with the addition of $6 \mathrm{wt} \%$ OPMF-CNW, the CNW 
percolation threshold. These different results may be explained by the nanofibers geometry and dispersion level within the polymer matrix.

\section{Conclusion}

Bionanocomposites were prepared from glycerol plasticized cassava starch and cellulose nanowhiskers extracted from oil palm mesocarp fibers. The reinforcing effect of the cellulose nanowhiskers was significant only for loading of up to $6 \mathrm{wt} \%$, increasing the elastic modulus. Below percolation threshold, elongation at break was even higher than neat starch films, it can be due to filler/matrix interaction in the bionanocomposites through hydrogen bonding. Above the percolation threshold, there was a formation of percolating cellulose nanowhiskers network, leading to nanowhiskers agglomeration and decrease of mechanical properties of the starch bionanocomposites. The aspect ratio and the dispersion of cellulose nanowhiskers are determining on thermomechanical properties of the bionanocomposites.

\section{Acknowledgments}

The authors gratefully acknowledge the financial support provided by CNPq (Process No. 383890/2014-4, 402287/2013-4, 303796/2014-6), FINEP, MCTI and Embrapa. The authors are also grateful to Milene Mitsuyuki Foschini for statistical analysis.

\section{References}

ASTM. (2013). Standard test method for tensile properties of thin plastic sheeting 1. American Society for Testing Materials, 14, 1-12. http://dx.doi.org/10.1520/ D0882-12

Anglès, M. N., \& Dufresne, A. (2001). Plasticized starch/tunicin whiskers nanocomposite materials. 2. Mechanical behavior. Macromolecules, 34, 2921-2931. http://dx.doi.org/10.1021/ma001555h

Arrieta, M. P., Fortunati, E., Dominici, F., López, J., \& Kenny, J. M. (2015). Bionanocomposite films based on plasticized PLA-PHB/cellulose nanocrystal blends. Carbohydrate Polymers, 121(November), 265-275. http://dx.doi.org/10. 1016/j.carbpol.2014.12.056

Balakrishnan, P., Sreekala, M. S., Kunaver, M., Huskić, M., \& Thomas, S. (2017). Morphology, transport characteristics and viscoelastic polymer chain confinement in nanocomposites based on thermoplastic potato starch and cellulose nanofibers from pineapple leaf. Carbohydrate Polymers, 169, 176-188. http://dx.doi.org/10.1016/j.carbpol.2017.04.017

Benhamou, K., Dufresne, A., Magnin, A., Mortha, G., \& Kaddami, H. (2014). Control of size and viscoelastic properties of nanofibrillated cellulose from palm tree by varying the TEMPO-mediated oxidation time. Carbohydrate Polymers, 99 , 74-83. http://dx.doi.org/10.1016/j.carbpol.2013.08.032

Camargo, L. A., Pereira, S. C., Correa, A. C., Farinas, C. S., Marconcini, J. M., \& Mattoso, L. H. C. (2016). Feasibility of manufacturing cellulose nanocrystals from the solid residues of second-generation ethanol production from sugarcane bagasse. Bioenergy Research, 9(3), 894-906. http://dx.doi.org/10.1007/s12155016-9744-0

Campos, A. D., de Neto, A. R. S., Rodrigues, V. B., Kuana, V. A., Correa, A. C., Takahashi, M. C., \& Marconcini, J. M. (2017). Production of cellulose nanowhiskers from oil palm mesocarp fibers by acid hydrolysis and microfluidization. Journal of Nanoscience and Nanotechnology, 17(7), 4970-4976. http://dx.doi.org/10.1166/jnn.2017.13451

Campos, A., Teodoro, K. B. R., Teixeira, E. M., Corrêa, A. C., Marconcini, J. M., Wood, D. F., \& Mattoso, L. H. C. (2013). Properties of thermoplastic starch and TPS/polycaprolactone blend reinforced with sisal whiskers using extrusion processing. Polymer Engineering E' Science, 53(4), 800-808. http://dx.doi.org/10. 1002/pen.23324

Campos, A., Tonoli, G. H. D., Marconcini, J. M., Mattoso, L. H. C., Klamczynski, A., Gregorski, K. S., \& Imam, S. H. (2013). TPS/PCL composite reinforced with treated sisal fibers: Property, biodegradation and water-absorption. Journal of Polymers and the Environment, 21(1), 1-7. http://dx.doi.org/10.1007/s10924012-0512-8

Cao, X., Chang, P. R., \& Huneault, M. A. (2008). Preparation and properties of plasticized starch modified with poly $(\varepsilon$-caprolactone $)$ based waterborne polyurethane. Carbohydrate Polymers, 71(1), 119-125. http://dx.doi.org/10. 1016/j.carbpol.2007.05.023

Celluforce. (2011). Nanocrystalline cellulose. http://celluforce.com/en/index.php

Curvelo, A. A. D. S., Carvalho, A. J. F., \& Agnelli, J. A. M. (2001). Thermoplastic starch cellulosic fibers composites: Preliminary results. Carbohydrate Polymers, 45 , $183-188$.
Dufresne, A., \& Castao, J. (2017). Polysaccharide nanomaterial reinforced starch nanocomposites: A review. Starch/Staerke, 69(1-2), 1-19. http://dx.doi.org/10. 1002/star.201500307

Fahma, F., Takemura, A., \& Saito, Y. (2014). Acetylation and stepwise solvent-exchange to modify hydrophilic cellulose whiskers to polychloroprene-compatible nanofiller. Cellulose, 21(4), 2519-2527. http://dx. doi.org/10.1007/s10570-014-0294-3

Ferrer, A., Filpponen, I., Rodríguez, A., Laine, J., \& Rojas, O. J. (2012). Valorization of residual Empty Palm Fruit Bunch Fibers (EPFBF) by microfluidization: Production of nanofibrillated cellulose and EPFBF nanopaper. Bioresource Technology, 125, 249-255. http://dx.doi.org/10.1016/j.biortech.2012.08.108

Garcia de Rodriguez, N. L., Thielemans, W., \& Dufresne, A. (2006). Sisal cellulose whiskers reinforced polyvinyl acetate nanocomposites. Cellulose, 13(3), 261-270. http://dx.doi.org/10.1007/s10570-005-9039-7

Kaisangsri, N., Kerdchoechuen, O., \& Laohakunjit, N. (2014). Characterization of cassava starch based foam blended with plant proteins, kraft fiber, and palm oil. Carbohydrate Polymers, 110, 70-77. http://dx.doi.org/10.1016/j.carbpol. 2014.03.067

Lamaming, J., Hashim, R., Sulaiman, O., Leh, C. P., Sugimoto, T., \& Nordin, N. A. (2015). Cellulose nanocrystals isolated from oil palm trunk. Carbohydrate Polymers, 127, 202-208. http://dx.doi.org/10.1016/j.carbpol.2015.03.043

Lani, N. S., Ngadi, N., Johari, A., \& Jusoh, M. (2014). Isolation, characterization and application of a cellulose-degrading strain Neurospora crassa S1 from oil palm empty fruit bunch. Microbial Cell Factories, 13(1), 157. http://dx.doi.org/10. 1186/s12934-014-0157-5

Leite, A. L. M. P., Zanon, C. D., \& Menegalli, F. C. (2017). Isolation and characterization of cellulose nanofibers from banana peels. Carbohydrate Polymers, 157, 962-970. http://dx.doi.org/10.1016/j.carbpol.2016.10.048

Li, X., Qiu, C., Ji, N., Sun, C., Xiong, L., \& Sun, Q. (2015). Mechanical, barrier and morphological properties of starch nanocrystals-reinforced pea starch films. Carbohydrate Polymers, 121(January), 155-162. http://dx.doi.org/10.1016/j. carbpol.2014.12.040

Liu, D., Dong, Y., Bhattacharyya, D., \& Sui, G. (2017). Novel sandwiched structures in starch/cellulose nanowhiskers (CNWs) composite films. Composites Communications, 4(March), 5-9. http://dx.doi.org/10.1016/j.coco.2017.03.001

Magalhães, N. F., \& Andrade, C. T. (2009). Thermoplastic corn starch/clay hybrids: Effect of clay type and content on physical properties. Carbohydrate Polymers, 75(4), 712-718. http://dx.doi.org/10.1016/j.carbpol.2008.09.020

Mathew, A. P., \& Dufresne, A. (2002). Plasticized waxy maize starch: Effect of polyols and relative humidity on material properties. Biomacromolecules, 3(5), 1101-1108. http://dx.doi.org/10.1021/bm020065p

Miao, X., Lin, J., Tian, F., Li, X., Bian, F., \& Wang, J. (2016). Cellulose nanofibrils extracted from the byproduct of cotton plant. Carbohydrate Polymers, 136, 841-850. http://dx.doi.org/10.1016/j.carbpol.2015.09.056

Nikmatin, S., Syafiuddin, A., \& Irwanto, D. A. Y. (2017). Properties of oil palm empty fruit bunch-filled recycled acrylonitrile butadiene styrene composites: Effect of shapes and filler loadings with random orientation. BioResources, 12(1), 1090-1101. http://dx.doi.org/10.15376/biores.12.1.1090-1101

Pasquini, D., Teixeira, E. D. M., Curvelo, A. A. D. S., Belgacem, M. N., \& Dufresne, A (2010). Extraction of cellulose whiskers from cassava bagasse and their applications as reinforcing agent in natural rubber. Industrial Crops and Products, 32(3), 486-490. http://dx.doi.org/10.1016/j.indcrop.2010.06.022

Salehudin, M. H., Salleh, E., Muhamad, I. I., \& Mamat, S. N. H. (2014). Starch-based biofilm reinforced with empty fruit bunch cellulose nanofibre. Materials Research Innovations, 18, S6-322. http://dx.doi.org/10.1179/1432891714z. 000000000977. S6-322-S6-325

Santana, J. S., do Rosário, J. M., Pola, C. C., Otoni, C. G., de Fátima FerreiraSoares, N., Camilloto, G. P., \& Cruz, R. S. (2017). Cassava starch-based nanocomposites reinforced with cellulose nanofibers extracted from sisal. Journal of Applied Polymer Science, 134(12), 1-9. http://dx.doi.org/10.1002/app.44637

Solikhin, A., Hadi, Y. S., Massijaya, M. Y., \& Nikmatin, S. (2016). Novel isolation of empty fruit bunch lignocellulose nanofibers using different vibration milling times-assisted multimechanical stages. Waste and Biomass Valorization, 1-12 http://dx.doi.org/10.1007/s12649-016-9765-0

Souza, N. F., Pinheiro, J. A., Silva, P., Morais, J. P. S., De Souza Filho, M. D. S. M., Brígida, A. I. S., . . \& \& De Freitas Rosa, M. (2015). Development of chlorine-free pulping method to extract cellulose nanocrystals from pressed oil palm mesocarp fibers. Journal of Biobased Materials and Bioenergy, 9(3), 372-379. http://dx.doi.org/10.1166/jbmb.2015.1525

Sreekala, M. S., Kumaran, M. G., \& Thomas, S. (1997). Oil palm fibers: Morphology, chemical composition, surface modification, and mechanical properties. Journal of Applied Polymer Science, 66(5), 821-835. http://dx.doi.org/10.1002/ (SICI)1097-4628(19971031)66:5<821::AID-APP2>3.0.CO;2-X

Teixeira, E. D. M., Pasquini, D., Curvelo, A. A. S., Corradini, E., Belgacem, M. N., \& Dufresne, A. (2009). Cassava bagasse cellulose nanofibrils reinforced thermoplastic cassava starch. Carbohydrate Polymers, 78(3), 422-431. http:// dx.doi.org/10.1016/j.carbpol.2009.04.034

van Soest, J. J. G., Hulleman, S. H. D., de Wit, D., \& Vliegenthart, J. F. G. (1996) Crystallinity in starch bioplastics. Industrial Crops and Products, 5(1), 11-22. http://dx.doi.org/10.1016/0926-6690(95)00048-8 